\section{STFM LAUNCHES INTERPROFESSIONAL LEADING CHANGE FELLOWSHIP}

STFM has launched a new yearlong fellowship for midcareer and senior faculty in clinical leadership roles.

The inaugural class of the Leading Change Fellowship will begin training at the 2015 STFM Conference on

Practice Improvement in December.

The fellowship curriculum and resources will educate and empower family medicine faculty to lead change within their institutions, larger surrounding environments, and at the national level. Throughout the fellowship year, teams will interact with mentors and attend training sessions at STFM conferences and via teleconference.

Fellows will participate as interprofessional dyads and will implement a practice change. "The day when a single person can do it all alone, whether administrative, financial, or clinical, is past," said John Franko, $\mathrm{MD}$, task force chair. "The dyad format recognizes that leadership, especially leadership around change, must include a highly functioning team and the dyad is the first step in that process."

Dyads in the inaugural class include:

- Tziporah Rosenberg, PhD, University of Rochester, and Mathew Devine, DO, Highland Family Medicine, Rochester, New York

- F. David Schneider, MD, and Craig Smith, PhD, St Louis University

- Jean Moon, PharmD, and Tanner Nissly, DO, University of Minnesota

- Joseph Teel, MD, and Heather Klusaritz, PhD, MSW, University of Pennsylvania

- Miranda Huffman, MD, MEd, and Lindsay Fazio, $\mathrm{PhD}$, Truman Medical Center, Kansas City, Missouri

- Cheyenne Rincones, RN, BSN, FNP-C, and Albert Campos,BS, Texas Tech University HSC, El Paso, Texas

- Ann Tseng, MD, and Karen Aiello, CMPE, Oregon Health \& Science University

- Briana Balderrama, LPN, and Daisuke Yamashita, MD, Oregon Health \& Science University

- Alicia Jacobs, MD, and Holly Whitcomb, APRNFNP, University of Vermont Medical Center

- Mark Drexler, MD, and Rita Yager, RN, University of Chicago Northshore FMR
"During the first year, I hope to see changes that are in line with the Quadruple Aim," said Jennifer Johnson, MSHS, co-chair of the Leading Change Fellowship.

\section{Not Part of this Year's Fellowship But Still Interested in Leading Change?}

STFM also offers an online Leading Change curriculum that was developed to educate and empower family medicine faculty to lead change within their institutions, larger surrounding environments, and their nation. The curriculum includes a series of 12 modules to help family medicine faculty at all levels of their careers plan for and implement change. Module topics include change leadership fundamentals, team building, change plan development, outcomes measurement, effective teamwork, and coaching skills.

The modules may be taken in any order, and a certificate is available upon completion of each module.

Modules include:

- Concepts Fundamental to Change Leadership

- Assess Needs \& Identify Opportunities for Change

- Create Urgency and Build the Team

- Construct a Plan for Change

- Establish and Measure Outcomes

- Launch Change

- Facilitate Effective Teamwork

- Celebrate and Capitalize on Success

- Coaching Strategies to Reinforce Change

- Leadership Wellness \& Improvement in the Face of Change

- Improvement Tools and Methodologies

- A Case Study

Traci Nolte, STFM

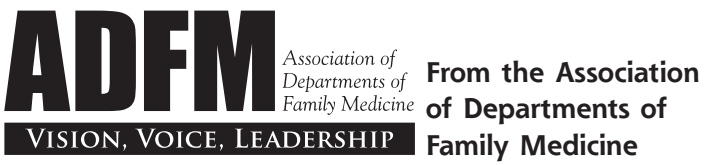

Ann Fam Med 2015;13:593-595. doi: 10.1370/afm.1873.

\section{PARTNERING FOR TRANSFORMATION: A MENU OF MANY POINTS OF ENTRY FOR YOUR DEPARTMENT}

Healthcare delivery transformation is happening at many different levels but these myriad activities all share one thing in common: they are impacted heavily by the old adage, "all politics are local." Recognizing that there are many points of entry to transformation, at many different system levels, the ADFM Healthcare Delivery Transformation Committee (HCDT) devel- 